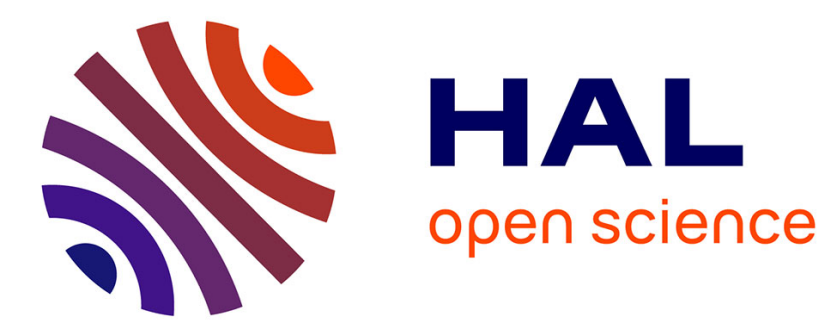

\title{
Hydrodynamics of gas-liquid co-current flow through a thin sheet of highly porous open cell solid foam
}

Thomas Busser, Marion Serres, Régis Philippe, Valerie Vidal

\section{To cite this version:}

Thomas Busser, Marion Serres, Régis Philippe, Valerie Vidal. Hydrodynamics of gas-liquid co-current flow through a thin sheet of highly porous open cell solid foam. Chemical Engineering Science, 2020, 226, pp.115811. 10.1016/j.ces.2020.115811 . hal-02966728

\section{HAL Id: hal-02966728 \\ https://hal.science/hal-02966728}

Submitted on 14 Oct 2020

HAL is a multi-disciplinary open access archive for the deposit and dissemination of scientific research documents, whether they are published or not. The documents may come from teaching and research institutions in France or abroad, or from public or private research centers.
L'archive ouverte pluridisciplinaire HAL, est destinée au dépôt et à la diffusion de documents scientifiques de niveau recherche, publiés ou non, émanant des établissements d'enseignement et de recherche français ou étrangers, des laboratoires publics ou privés. 


\title{
Hydrodynamics of gas-liquid co-current flow through a thin sheet of highly porous open cell solid foam
}

\author{
Thomas Busser ${ }^{\mathrm{a}}$, Marion Serres ${ }^{\mathrm{a}, \mathrm{b}, \mathrm{c}}$, Régis Philippe ${ }^{\mathrm{b}}$, Valérie Vidal ${ }^{\mathrm{a}, *}$ \\ ${ }^{a}$ Univ Lyon, ENS de Lyon, Univ Claude Bernard, CNRS, Laboratoire de Physique, \\ 46 Allée d'Italie, 69364 Lyon, France \\ ${ }^{b}$ Univ Lyon, CPE Lyon, Univ Claude Bernard, CNRS, Laboratoire de Génie des Procédés Catalytiques, \\ 43 bd du 11 novembre 1918, 69616 Villeurbanne, France \\ ${ }^{c}$ IFPEN - IFP Energies Nouvelles, Rond-point de l'échangeur de Solaize, 69360 Solaize, France
}

\begin{abstract}
An experimental study of the hydrodynamics of a gas-liquid co-current flow inside a thin sheet of Open Cell Solid Foam (OCSF) confined in a plate reactor is proposed. Image processing is used to quantify the flow patterns when varying the gas and liquid flow rates and buoyancy (horizontal and vertical upflow). The fraction of joint flow and interface motion areas, respectively $\varepsilon_{m}$ and $\varepsilon_{i}$, are defined as relevant quantities to characterize the different flow regimes and phases interaction. Two distinct regimes are observed for the vertical flow: the low (LA) and high (HA) activity regimes characterized by a low or high phases interaction. In the horizontal configuration, an additional regime is observed and is called pseudo-trickling $(\mathrm{PT})$ regime due to its similarity with the trickling regime observed in vertical downflow packed beds. The transition between LA and HA regimes is compared to the regime transition in trickle beds.
\end{abstract}

Keywords: hydrodynamics, multiphase flows, porous medium, open cell solid foam.

\section{Introduction}

Multiphase flows are widely encountered in chemical engineering [1], from distillation and absorption processes [2-4] to multiphase catalytic reactors [5-7] or transport in electrolyte fuel cells [8]. In the specific field of reaction engineering, a variety of multiphase contact principles have been developed to optimize the contact between gas and liquid reactants with a solid that can be a heterogeneous catalyst, an inert structure or also a reactant. The choice of the appropriate contact principle depends on various constraints (size and geometry, energy

\footnotetext{
${ }^{*}$ Corresponding author

Email address: valerie.vidal@ens-lyon.fr (Valérie Vidal)

Preprint submitted to Elsevier
}

consumption, costs, coupling with chemical kinetics, deactivation, etc...) which relevance can change from one application to the other. Therefore, an extensive literature can be found on the study of gas-liquid flows through porous media and the different hydrodynamic regimes and associated patterns. In particular, packed beds have been thoroughly investigated, with a special focus on downflow or trickle bed configurations which are commonly encountered in industrial reactors [9-15].

Since 15 years and the pionnering work of Stemmet et al. [16-19], open cell solid foams (OCSFs) are studied and developed as alternative to dense packed beds. Main applications range from (reactive) distillation $[20,21]$ to heterogeneous catalysis with gas-liquid-solid

May 12, 2020 
(G-L-S) reactors [22-31]. Compared to packed beds, these innovative materials offer a relatively high surface contact area combined to a very high porosity, resulting in efficient phases transport and low pressure loss. The use of these new materials is therefore promising for the optimization of G-L-S multiphase contact.

Previous studies focused on the ability of different solid foams (metallic or not) to increase the gas-liquid mass transfer. Classical techniques are mainly based on global measurements such as pressure loss, residence time distribution or liquid hold-up [16, 17, 19, 28, 32]. To get a better insight on the local flow dynamics, more recent experimental methods were developed. Millichannel (quasi-1D) experiments were coupled to direct visualization and made possible to identify the different flow patterns $[28,29,33,34]$. In unconfined (3D) experiments, the flow cannot be visualized directly and heavier or more costly methods can be employed such as X-ray, $\gamma$-ray or impedance tomography techniques [35-40]. Although few studies have focused on the flow regimes in such materials [41, 42], the effect of confinement and/or buoyancy on the contact between phases still remains a fundamental issue. In particular, there is at present a gap of knowledge between strongly confined flows in millichannels and large reactors. Plate reactors with OCSFs could represent a real potential for chemical engineering applications, and there is a strong need for a fundamental comprehension of the flow regimes in such configurations. More specifically, the following questions deserve a thorough investigation: What are the flow regimes for G-L flows in plate reactors? Which quantities describe accurately the multiphase contact? Can the regime(s) transition be described by the empirical laws found in the literature for packed beds, with a simple porosity correction?

This work investigates experimentally a cocurrent gas-liquid flow through a thin sheet of an open-cell metallic foam, both in a vertical (upflow) and horizontal configuration to quantify the effect of buoyancy (section 2). The multiphase flow characteristics are described from direct visualization. We introduce two new quantities which quantify the phases interaction, the fraction of G-L joint flow area, $\varepsilon_{m}$, and interface motion, $\varepsilon_{i}$ (section 3 ). Different hydrodynamic regimes are quantified both in the vertical and horizontal geometries. The regime transition is discussed and compared to the scaling laws proposed in the literature for dense packed beds (section 4).

\section{Experimental setup}

\subsection{Description}

The experimental setup consists of a quasibidimensional reactor, so-called Hele-Shaw cell, of width $W=20 \mathrm{~cm}$ and total height $40 \mathrm{~cm}$ (Figure 1a). The two tempered glass panels of $6 \mathrm{~mm}$ thickness are sealed within a frame made of PEEK (polyether ether ketone), a solid thermoplastic polymer often used for its strong mechanical and chemical resistance. A gap $e=1.75 \pm 0.05 \mathrm{~mm}$ is ensured between the plates using a silicone seal inserted into a groove on one of the PEEK supports, also ensuring the cell tightness. The cell gap is very small compared to its height and width, ensuring a confined, quasi two-dimensional flow. In addition, the cell is fixed to a mechanical structure which makes it possible to adjust its orientation. In this work, we focus on the vertical and horizontal configurations.

The gas-liquid co-current flow is generated at the base of the cell as follows. The liquid (deionized water, density $\rho_{L}=$ $1000 \mathrm{~kg} \cdot \mathrm{m}^{-3}$ ) is injected at a constant flow rate $Q_{L}$ [100-1000 $\left.\mathrm{mL} / \mathrm{min}\right]$ using a magnetic drive pump (Bronkhorst Tuthill DXS1.6PPT2NNM103) coupled to a Coriolis flow controller (Bronkhorst CORI-FLOW). To ensure a stable and homogeneous liquid flow, the liquid phase fills a homogenizing chamber drilled into the PEEK frames before entering the cell (Figure 1b). The gas (air, density $\rho_{G}=$ 


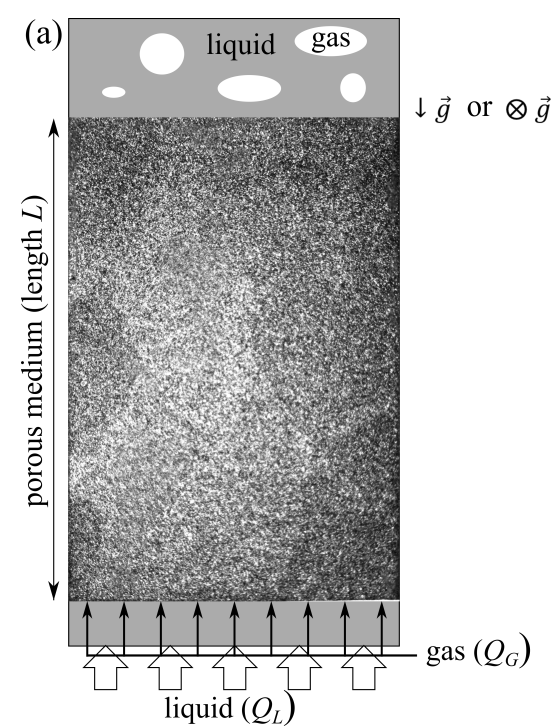

(b)

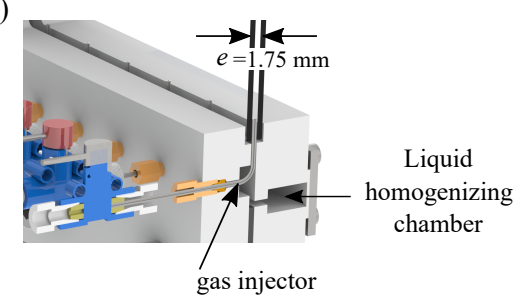

Figure 1: (a) Simplified scheme of the quasi-2D cell with a porous medium. The cell can be oriented in the vertical or horizontal position. (b) Section of the experimental device near a gas injector, showing the cell gap $e$ and the fluids (gas and liquid) injection system. A homogenizing chamber makes it possible to inject homogeneously the liquid phase through the above slit.

$1.2 \mathrm{~kg} \cdot \mathrm{m}^{-3}$ ) is pushed in the cell at a total constant flow rate $Q_{G}[100-1900 \mathrm{~mL} / \mathrm{min}]$ through nine injectors connected to a gas flow controller (Alicat MC-5SLM-D/CM-C2M). The injectors have an outer diameter of $1 / 16$ " and an inner diameter of $0.0345 "(\simeq 0.88 \mathrm{~mm})$. They are evenly distributed at the cell base (Figure 1b) and are directly in contact with the base of the porous medium (Figure 1a). After crossing the porous medium, the gas-liquid flow leaves the cell by a collector. The liquid phase is then recycled, which enables the experiment to work in closed loop. Note that, to ensure a uniform gas distribution, needle valves are mounted upstream each gas injector. Their adjustment is performed before all experimental series in an empty cell (without porous medium) filled with liquid, and the gas distribution uniformity is controlled optically.

Direct visualization of the flow through the porous medium is ensured by a light panel (Euroshopled) connected to a stable continuous power supply (TENMA 72-2545). The light panel is located behind the cell and illuminates homogeneously the device. The image acquisition is performed by a camera (Basler A2040$90 \mathrm{um}, 2048 \times 2048$ pixels $)+16 \mathrm{~mm}$ lens) located in front of the cell at a distance of about $50 \mathrm{~cm}$ in both the vertical and horizontal configurations. In all experiments, the frame rate is fixed to $100 \mathrm{fps}$, for a total duration of $30 \mathrm{~s}$ (see section 2.3 for the experimental protocol).

\subsection{Porous medium}

The porous medium in the experiments is an open cell solid foam made of an alloy $\mathrm{NiCrFeAl}$ (Alantum). Not many materials are available as thin solid foam sheets with precise thickness. This alloy was one good candidate, being also inert. The OSCF thin sheet occupies the entire section of the cell (width and gap) and has a length $L=28.7 \mathrm{~cm}$, lower than the total cell height $(40 \mathrm{~cm})$ so that the gas and liquid flow can escape freely but still in a confined geometry after crossing the porous medium. The OSCF characteristics provided by the supplier (Alantum) are given in Table 1 (upper part). For sake of comparison, a simple calculation for packed beds of spherical particles gives a specific geometric surface area (GSA) $a_{S}=6(1-\varepsilon) / d_{p}$, where $d_{p}$ is the particle diameter and $\varepsilon$ the bed porosity. For a random packing, $\varepsilon \simeq 40 \%$, leading to a particle diameter of $522 \mu \mathrm{m}$. For an equivalent $a_{S}$, the OSCF used in this work has a porosity of $90 \%$, which implies a much lower pressure loss for multiphase flow crossing this innovative material, and thus a great potential for further chemical reactions.

To have a better insight on the structure of the material, images were acquired with a digital microscope (Keyence VHX 6000) at different magnifications (Figure 2). The solid foam 


\begin{tabular}{c|c|c}
\hline \hline Properties & Value & Unit \\
\hline \hline Porosity & 90 & $\%$ \\
$a_{S}$ (GSA) & 6900 & $\mathrm{~m}^{2} / \mathrm{m}^{3}$ \\
Pore diameter & 580 & $\mu \mathrm{m}$ \\
\hline Cells diameter & $608 \pm 38$ & $\mu \mathrm{m}$ \\
Windows diameter & $376 \pm 45$ & $\mu \mathrm{m}$ \\
Struts diameter & $82 \pm 12$ & $\mu \mathrm{m}$ \\
Struts length & $352 \pm 53$ & $\mu \mathrm{m}$ \\
\hline
\end{tabular}

Table 1: Characteristics of the $\mathrm{NiCrFeAl}$ open cell solid foam from the supplier (Alantum, upper part of the table) and from measurements based on microscope imaging (this study, lower part of the table). $a_{S}$ is the specific geometric surface area (GSA).

structure is composed by struts and the void fraction can be divided into two subunits, cells and windows. The cells correspond to the void cages enclosed by the struts, while the windows are the junctions between two cells. The mean diameter and corresponding standard deviation of these three structural units were estimated from image analysis and are reported in Table 1 (lower part). Note that the measured mean cells diameter is comparable to the one provided by the supplier. Additional information concerning the foam is provided in Supplemental Material A.1).

\subsection{Experimental protocol}

To ensure a good reproducibility of the experiments, the following protocol is applied for each experimental series. First, the cell is totally flushed and filled with the liquid phase by applying a low flow rate $\left(Q_{L}=30 \mathrm{~mL} / \mathrm{min}\right)$ while keeping the gas injectors closed. This ensures the elimination of possible trapped gas bubbles and avoids the formation of preferential paths. Then, the liquid flow is set to a given value $Q_{L}$ and consecutively the gas flow rate $Q_{G}$ is fixed. The nine gas injectors are quickly opened manually, from the cell center to its sides. No difference was reported in the experimental results when changing the opening sequence, as long as it was performed rapidly (a few seconds at most). Thanks to the needle valves, the pressure drop is the same for (a)

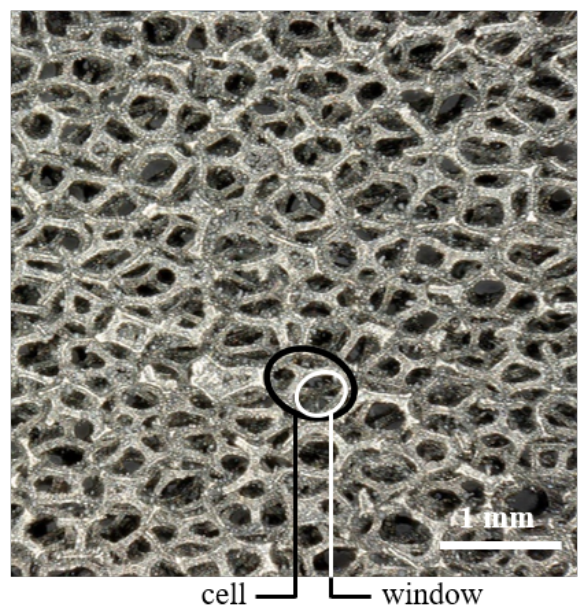

(b)

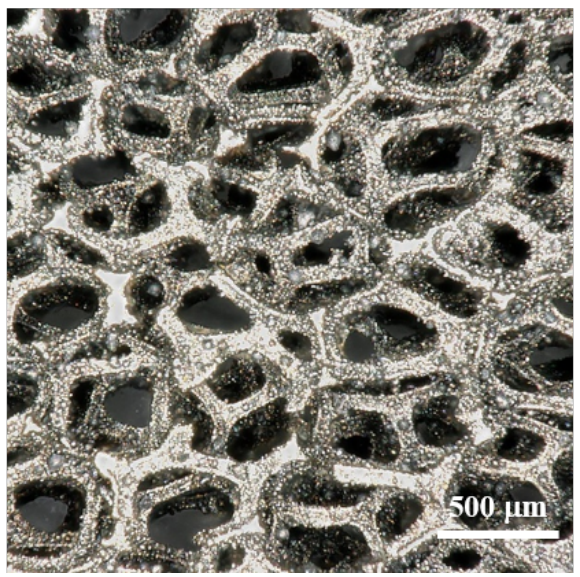

Figure 2: Open cell solid foam $\mathrm{NiCrFeAl}$ (Alantum) visualized by a digital microscope with different magnifications (a) $\times 50$, (b) $\times 100$. A cell (black contour) and a window (white contour) are highlighted in (a).

each injector, thus ensuring a uniform gas distribution (see section 2.1).

The time required to reach a stationary regime was estimated as follows. The intensity map obtained by performing the difference between two successive images provides an estimation of the motion in the system. We considered that the flow is in stationary state when the average value of this intensity map reaches a constant value and does not exhibit strong fluctuations anymore. For all flow rates, the associated time was always smaller or equal to $4 \mathrm{~min}$. Therefore, in all experiments, after imposing $Q_{L}$ and $Q_{G}$, we waited typically $5 \mathrm{~min}$ before starting the images acquisition. 


\subsection{Confinement effects}

As stated above (section 2.1), the cell gap $e$ is small, providing a quasi-2D flow. This confined environment was set on purpose to enhance contact between the solid, gas and liquid phases by forcing the gas/liquid flow through the gap. As detailed in the next sections, most of the regions occupied by the gas have a typical size much larger than the gap size $e$. In such case, the lubrication films between the gas and the cell walls have a thickness $h$ which can be estimated as $[43,44]$

$$
\frac{h}{e} \sim \frac{C a^{2 / 3}}{1+C a^{2 / 3}}
$$

where $C a=\eta U / \sigma$ is the capillary number, $\eta=10^{-3}$ Pa.s the fluid dynamic viscosity, $U$ the gas velocity and $\sigma=72 \mathrm{mN} . \mathrm{m}^{-1}$ the air/water surface tension. The gas velocity does not exceed a few tens of centimeters per second in our experiments, leading to $C a \ll 1$ and hence $h \ll e$. We can therefore consider, in the following, that the gas occupies all the cell gap.

\section{Data processing}

\subsection{Gas and liquid phases}

The first step in data processing is to identify the location of the liquid and gas phases in the porous medium at each time step. To do so, all images of a time sequence, $I_{n}$, are divided by a reference image $I_{0}$ corresponding to the cell completely filled with liquid, taken before opening the gas valves (Figures 3a,b). An algorithm (Matlab R2017b, Mathworks ${ }^{\circledR}$ ) based on morphological analysis is then applied. It makes possible to binarize the images so that each pixel in the resulting matrix $I_{n, b}$ is 1 if it is occupied by the solid foam or liquid phase, and 0 if it is occupied by the gas phase.

\subsection{Joint flow}

The binarized images $I_{n, b}$ are used to compute the fraction $\varepsilon_{m}$ of the porous medium in which an alternation between gas and liquid has been observed in time (also called fraction of joint flow area). First, we compute the probability $p_{\text {liq }}$ of liquid occupation at each coordinates $(x, y)$ in the foam:

$$
p_{l i q}(x, y)=\frac{1}{N} \sum_{n=1}^{N} I_{n, b}(x, y)
$$

where $N$ is the total number of images in the sequence (Figure 3c). The joint flow region is then defined as the region where the gasliquid alternation was such that the liquid or gas phase remained less than $70 \%$ of the total experimental time, $30 \%<p_{\text {liq }}<70 \%$ (Figure $3 \mathrm{~d}$ ). The proportion of joint gas-liquid flow in the foam, $\varepsilon_{m}$, is finally defined as the ratio between the joint flow area and the foam area:

$$
\varepsilon_{m}=\frac{\mathcal{A}\left(30 \%<p_{\text {liq }}<70 \%\right)}{L W} .
$$

\subsection{Interface motion}

The second variable estimated from the binarized image sequences is $\varepsilon_{i}$, the fraction of interface motion, corresponding to the percentage of the image in which the gas-liquid interfaces have moved in time. At each time step, we compute the absolute value of the difference between two successive images, $I_{n}$ (Figure 3a) and $I_{n+1}$ (Figure 3e), $\left|I_{n+1}-I_{n}\right|$ (Figure 3f). This latter displays clearly the regions where motion occurred in the system. This movement is directly linked to the gas-liquid interface motion in the system, which is of drastic importance in terms of applications to further chemical reactions between phases, as it is representative of the gas-liquid-solid contact area. The pixels associated with interface motion have a value much larger than the pixels characteristic of still zones (strictly equal to zero). A simple binarization is therefore applied $\left(\left|I_{n+1}-I_{n}\right|_{b}\right)$ and its average value computed over the total image sequence, giving the probability $p_{\text {int }}$ of interface motion at each pixel $(x, y)$ :

$$
p_{\text {int }}(x, y)=\frac{1}{N} \sum_{n=1}^{N-1}\left|I_{n+1}(x, y)-I_{n}(x, y)\right|_{b}
$$



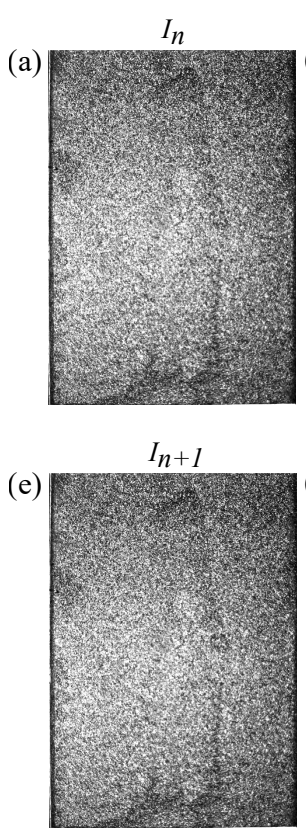
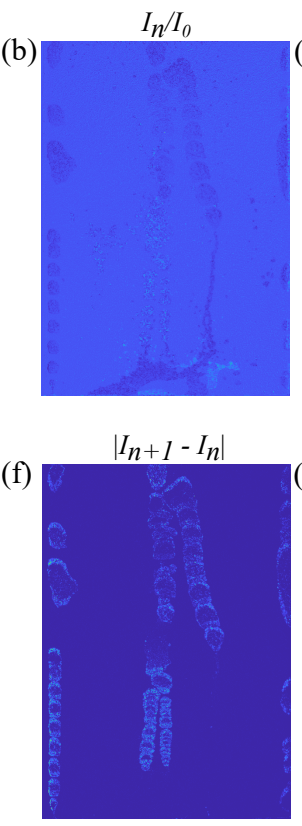
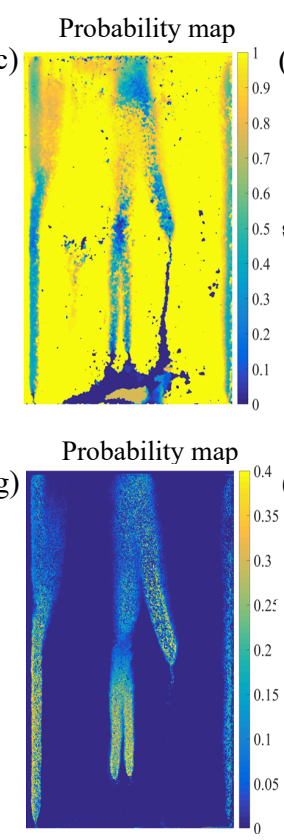

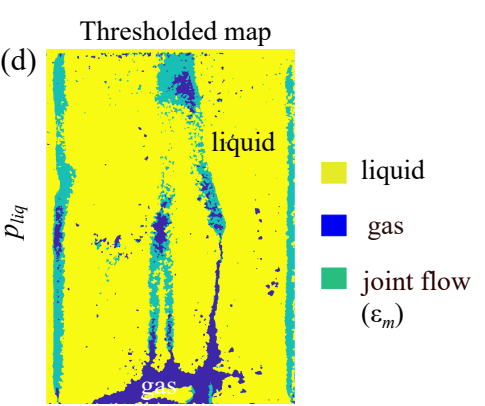

Thresholded map (h)

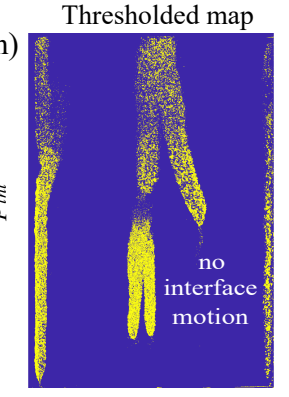

interface motion

$\left(\varepsilon_{i}\right)$

no interface

motion

Figure 3: Illustration of data processing and computation of the fraction of joint flow area $\varepsilon_{m}$ and of interface motion area $\varepsilon_{i}$ [vertical co-current upflow, $Q_{G}=400 \mathrm{~mL} / \mathrm{min}, Q_{L}=700 \mathrm{~mL} / \mathrm{min}$, see Supplemental Material A.1, Movie 1]. (a) Raw image $I_{n}$ from data acquisition at the time step $n$. Note that it is difficult to distinguish the position of the gas and liquid phases. (b) Image $I_{n}$ divided by the reference image $I_{0}$ corresponding to the foam completely filled with liquid. (c) Map of the probability of liquid occupation, $p_{l i q}$. (d) Thresholded probability map (from (c)) displaying the regions mainly occupied by the liquid phase (yellow, $p_{l i q}>70 \%$ ) or the gas phase (blue, $p_{l i q}<30 \%$ ) and the joint flow region (green, $\left(30 \%<p_{l i q}<70 \%\right.$ ). (e) Raw image $I_{n+1}$ from data acquisition at the time step $(n+1)$. (f) Absolute value of the successive images difference $\left|I_{n+1}-I_{n}\right|$. (g) Map of the probability of interface motion, $p_{\text {int }}$. (h) Thresholded probability map (from $(\mathrm{g})$ ) displaying the regions for which interface motion occurred in the system (yellow, $p_{\text {int }}>10 \%$ ).

\section{(Figure 3g).}

The interface motion region is then defined as the region for which $p_{\text {int }}>10 \%$ (Figure $3 \mathrm{~h}$ ). The fraction of interface motion, $\varepsilon_{i}$, is finally computed as the ratio between the area of the interface motion region and the total foam area:

$$
\varepsilon_{i}=\frac{\mathcal{A}\left(p_{i n t}>10 \%\right)}{L W} .
$$

\section{Results \& Discussion}

\subsection{Influence of buoyancy}

Figure $4 \mathrm{a}$ shows the evolution of $\varepsilon_{m}$ as a function of the liquid flow rate $Q_{L}$, at fixed $Q_{G}$. The increase in $Q_{L}$ seems to have a direct impact on $\varepsilon_{m}$ in the horizontal configuration respect to the vertical flow. Indeed, for the latter, at $Q_{L}>400 \mathrm{~mL} / \mathrm{min}$, all data points fluctuate around a stable mean value. However, these results are unfortunately incomplete for horizontal flows due to the fact that for $Q_{L} \geq 250 \mathrm{~mL} / \mathrm{min}$ the image processing fails (see section 5). The data point in Figure 4a at $Q_{L}=150 \mathrm{~mL} / \mathrm{min}, \varepsilon_{m} \simeq 30 \%$ has been checked, and is an outlier. Figure $4 \mathrm{~b}$ presents the evolution of $\varepsilon_{m}$ as a function of the gas flow rate $Q_{G}$, at fixed $Q_{L}$. The increase in $Q_{G}$ impacts stronly the evolution of $\varepsilon_{m}$ in the vertical flow, with a steady increase up to $\varepsilon_{m} \simeq 30 \%$ at the maximum gas flow rate possible with our experimental setup. In contrast, the value of $\varepsilon_{m}$ in the horizontal flow remains almost constant and is always much lower compared to the vertical flow. This last observation indicates that $\varepsilon_{m}$ is strongly influenced by the buoy- 


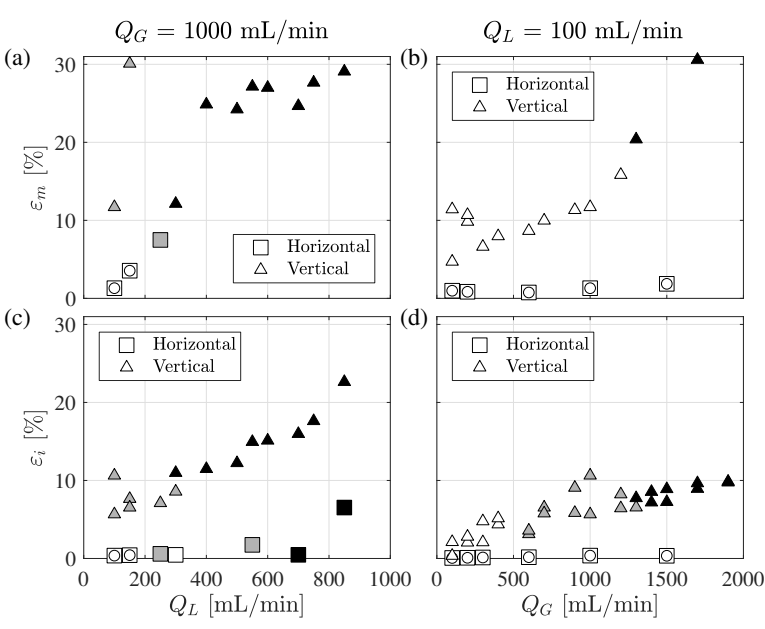

Figure 4: (a) Fraction of joint flow area, $\varepsilon_{m}$, as a function of the liquid flow rate $Q_{L}\left[Q_{G}=1000 \mathrm{~mL} / \mathrm{min}\right]$. (b) $\varepsilon_{m}$ as a function of the gas flow $Q_{G}\left[Q_{L}=\right.$ $100 \mathrm{~mL} / \mathrm{min}]$. (c) Fraction of interface motion area, $\varepsilon_{i}$, as a function of the liquid flow rate $Q_{L}\left[Q_{G}=\right.$ $1000 \mathrm{~mL} / \mathrm{min}]$. (d) $\varepsilon_{i}$ as a function of the gas flow rate $Q_{G}\left[Q_{L}=100 \mathrm{~mL} / \mathrm{min}\right]$. The colors indicate the hydrodynamic regimes discussed in section 4.2 and displayed in Figure 7 [white $=$ LA regime, gray $=$ transition regime, black $=$ HA regime, white squares with circle inside $=\mathrm{PT}$ regime $]$.

ancy, and that joint flow areas are improved when the cell is in the vertical configuration. Note that a good reproducibility is found for the estimation of $\varepsilon_{m}$. Figure $4 \mathrm{~b}$ shows data sets from different experiments but same imposed conditions (here $Q_{G}=200 \mathrm{~mL} / \mathrm{min}$ and $\left.Q_{L}=100 \mathrm{~mL} / \mathrm{min}\right)$. The values of $\varepsilon_{m}$ are very close, with a difference of less than a few percents.

Figures $4 \mathrm{c}$ and $\mathrm{d}$ present the variation of $\varepsilon_{i}$ as a function of either the liquid flow rate or the gas flow rate (the other being kept constant). Similarly to $\varepsilon_{m}, \varepsilon_{i}$ is always larger for the vertical flow than for the horizontal flow. The impact of the liquid flow rate on the interface motion seems larger, as it leads to a stronger increase in $\varepsilon_{i}$ than the gas flow rate. For a fixed $Q_{L}$ (Figure $4 \mathrm{~d}$ ), the difference in $\varepsilon_{i}$ for the vertical and horizontal flow is lower, especially for low gas flow $\left(Q_{G}<300 \mathrm{~mL} / \mathrm{min}\right)$. Note also that the reproducibility in $\varepsilon_{i}$ was also carefully checked. The same conditions of liquid and gas flows were tested several time and the results reported in Figures 4c and d. Within a few percents, the measurements are in fair agreement.

Although the image processing relying on the images morphological analysis fails in estimating $\varepsilon_{m}$ when the liquid flow rate is large in the horizontal configuration, the experimental results comparing the effect of buoyancy on $\varepsilon_{m}$ are displayed in Figures 5a and b. They confirm that the joint flow area is strongly enhanced by buoyancy (vertical vs. horizontal configuration) and by the gas flow rate, while the liquid flow rate has a much lower impact on the increase of $\varepsilon_{m}$. Results for $\varepsilon_{i}$ are more numerous, as they are less sensitive to the analysis, especially in the horizontal configuration. Figures 5c and d summarize the experimental results and their interpolation for the vertical (Figure 5c) and the horizontal (Figure 5d) flow. The interface motion is almost negligible for a wide range of gas and liquid flow rates in the horizontal configuration, where $Q_{L}$ has to be higher than $500 \mathrm{~mL} / \mathrm{min}$ to observe an increase in $\varepsilon_{i}$ (Figure $5 \mathrm{~d}$ ). In the vertical configuration, $\varepsilon_{i}$ is strongly impacted by both the gas and liquid flow rates. As soon as an additional energy is supplied to the flow, the interface movements are distributed over a large area in the porous medium thanks to the buoyancy of the gas bubbles and the inertia of the liquid phase which can deviate the gas bubbles from their trajectories.

\subsection{Different hydrodynamic regimes}

By varying the gas and liquid flow rates $\left(Q_{G}, Q_{L}\right)$, different flow regimes were observed, characterized by different displacement patterns. The classification of these regimes was based on the probability maps of both the liquid phase occupation, $p_{l i q}$ (top images, Figure 6), and the interface motion, $p_{\text {int }}$ (bottom images, Figure 6). In all this section, for sake of clarity, each couple of gas and liquid flow rate will be indicated $\left(Q_{G}, Q_{L}\right)$, for instance 

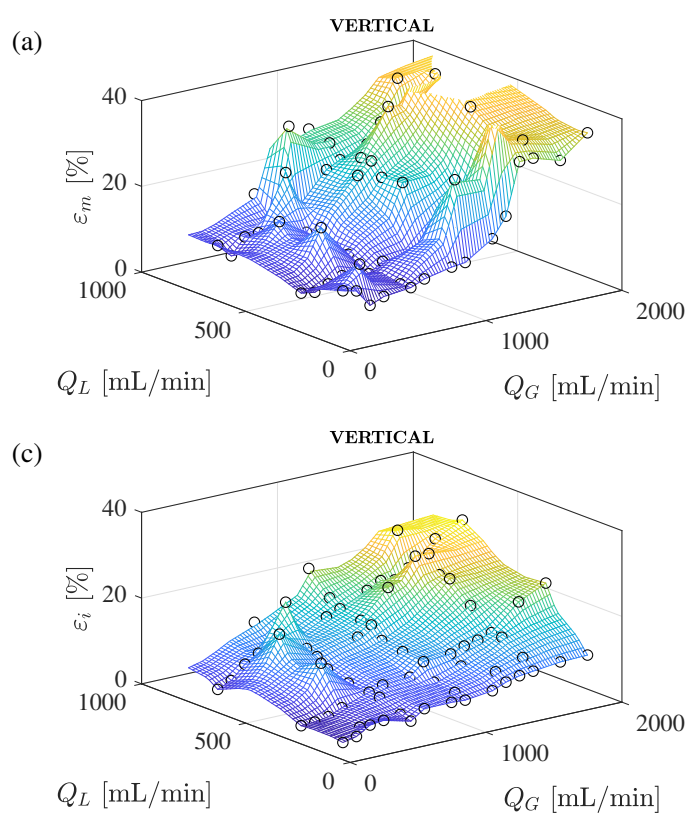
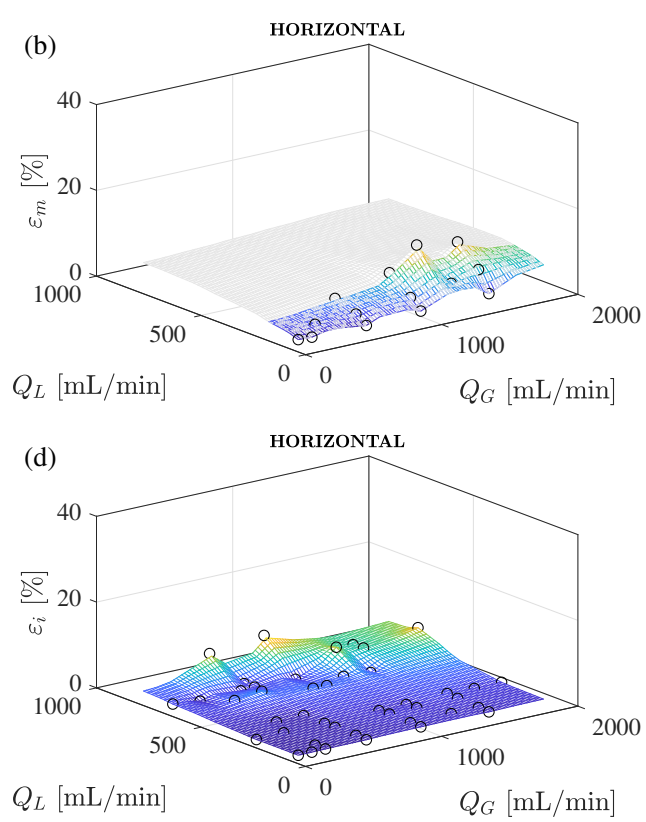

Figure 5: Evolution of the fraction of joint flow area, $\varepsilon_{m}(\mathrm{a}, \mathrm{b})$ and of the fraction of interface motion, $\varepsilon_{i}(\mathrm{c}, \mathrm{d})$ as a function of $Q_{L}$ and $Q_{G}$ for the vertical (a,c) and horizontal (b,d) flows. The circles represent the experimental points, and the colored surface their interpolation (Matlab function interp2). For sake of comparison, the axes were fixed to the same range for both variables and configurations. The gray area in (b) for $Q_{L}>250 \mathrm{~mL} / \mathrm{min}$ indicates the region where no $\varepsilon_{m}$ determination was possible (see text).

$(100,100)$, where the values of $Q_{G}$ and $Q_{L}$ are in $\mathrm{mL} / \mathrm{min}$.

\section{- Pseudo-trickling (PT)}

At low gas and liquid flow rate $(100,100)$, in the horizontal configuration, the gas and liquid phases are mostly separated (Figure 6a) and the flow does not display any significant interface motion (Figure 6d). We name this flow pseudo-trickling as it presents strong similarities with classical trickle flows, although slow movements of the gas phase are observed in our experiments. This regime is not observed in the vertical configuration because even at low flow rate, the gas phase rises due to buoyancy.

\section{- Low activity (LA)}

This regime is observed for both the horizontal and vertical configurations. Examples of the associated probability maps are given in Figures 6b,e $(1200,250)$ for the horizontal and Figures $6 \mathrm{~g}, \mathrm{i}(400,700)$ for the vertical flow. It is characterized by three types of structures: (1) Regions only occupied by the liquid phase $\left(p_{l i q} \simeq 1\right.$, yellow areas, Figure $\left.6 \mathrm{~b}\right)$ and without any interface motion $\left(p_{\text {int }} \simeq 0\right.$, dark blue areas, Figure 6e); (2) Trains of small bubbles separated by slugs of liquid, flowing through preferential paths $\left(0.4 \lesssim p_{\text {liq }} \lesssim 0.6\right.$, Figures $6 \mathrm{~b}$,g and $p_{\text {int }} \simeq 0.15$, Figures $\left.6 \mathrm{c}, \mathrm{i}\right) ;(3)$ Chimneys consisting of a continuous and stationary gas channel; in these zones $p_{\text {int }} \simeq 0$ on the heart and $p_{\text {int }} \simeq 0.15$ for the edges. In this regime, the gas-liquid interface mobility is relatively small, which makes it easy to identify by simply visualizing the image sequences.

- High activity (HA)

This last regime is observed for high values of flow rates in both the horizontal $(1500,750)$ and vertical $(1400,600)$ configurations (Figures $6 \mathrm{c}, \mathrm{f}$ and $h, j)$. It is characterized by the same structures as the ones described for the low activity regime but in different proportions. Ar- 

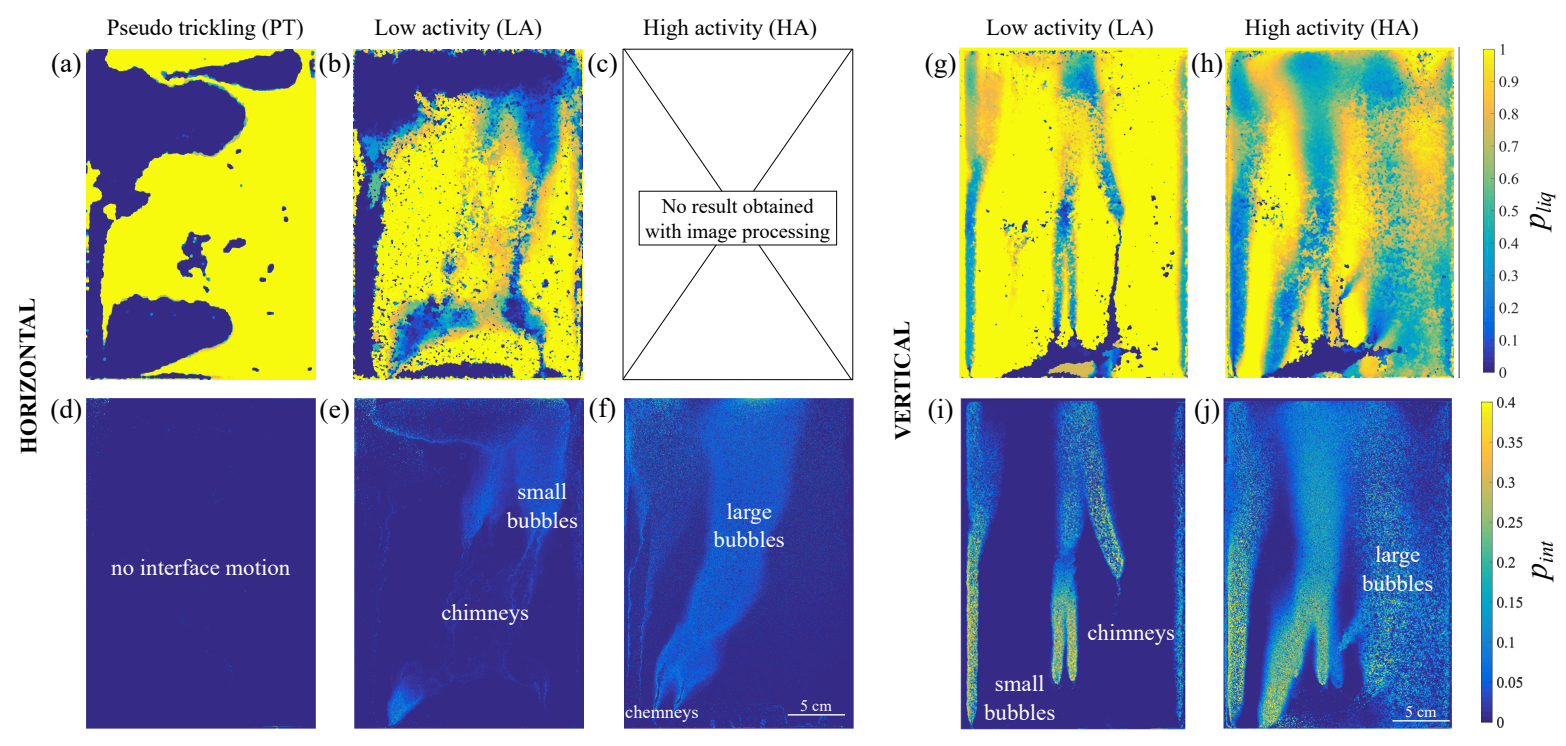

Figure 6: Probability maps of the liquid occupation, $p_{\text {liq }}$, (a-c,g-h) and of interface motion, $p_{\text {int }}$ (d-f, i-j) for the horizontal (left) and vertical (right) flow with three different flow rates representative of the different hydrodynamic regimes (see corresponding movies in Supplemental Materials A.1, Movies 1 to 5). $\left(Q_{G}, Q_{L}\right)$ are indicated in the following in $\mathrm{mL} / \mathrm{min}$. Horizontal configuration: (a,d) Pseudo-trickling PT (100,100); (b,e) Low activity LA (1200,250); (c,f) High activity HA (1500,750). Vertical configuration: (g,i) Low activity LA (400,700); (h,j) High activity HA $(1400,600)$. No pseudo-trickling (PT) regime is observed in the vertical configuration.

eas without interface mobility $\left(p_{\text {int }} \simeq 0\right)$ are smaller and the chimneys have almost disappeared. Therefore, there are more "active" zones in terms of interfaces motion, with the existence of preferential paths for larger bubbles. This regime is thus called the "high activity regime", and can clearly be distinguished as an increase of activity in the system (Figures $6 f, j$ ). For high values of the flow rates, the image processing technique based on morphological analysis fails in computing the probability maps of liquid occupation, $p_{\text {liq }}$, in the horizontal configuration (Figure 6c).

Note that the low and high activity regimes differ from the commonly named low and high interaction regimes. These latter are used in the literature to distinguish the flow regimes in the specific configuration of trickle bed reactors, in which the low interaction regime refers to the trickle flow regime (no joint flow or interface motion), while the high interaction regime describes pulsing, bubbling or wavy flows [4547].

\subsection{Regime diagram}

The different hydrodynamic regimes observed in the experiments are reported in a regime diagram in the phase space $\left(Q_{L}, Q_{G}\right)$ for both the horizontal (squares) and vertical (triangles) configurations (Figure 7). The white symbols correspond to the low activity (and pseudo-trickling with circle inside for the horizontal co-current flow only) and the black symbols to the high activity regime. Although the LA and HA regimes occupy welldefined regions, for some experiments, it was difficult to distinguish between both regimes. As it was not possible from the flow patterns to recognize a pure LA or HA regime, we defined a transition regime ( $\mathrm{T}$, gray symbols in Figure 7), which indicates that the transition between the hydrodynamic regimes is smooth and continuous. The reproducibility in the regime identification was tested by repeating the experiments for different flow rates $\left(Q_{G}, Q_{L}\right)$ (see AppendixA and Figure A.9). Except marginally at the boundaries between 

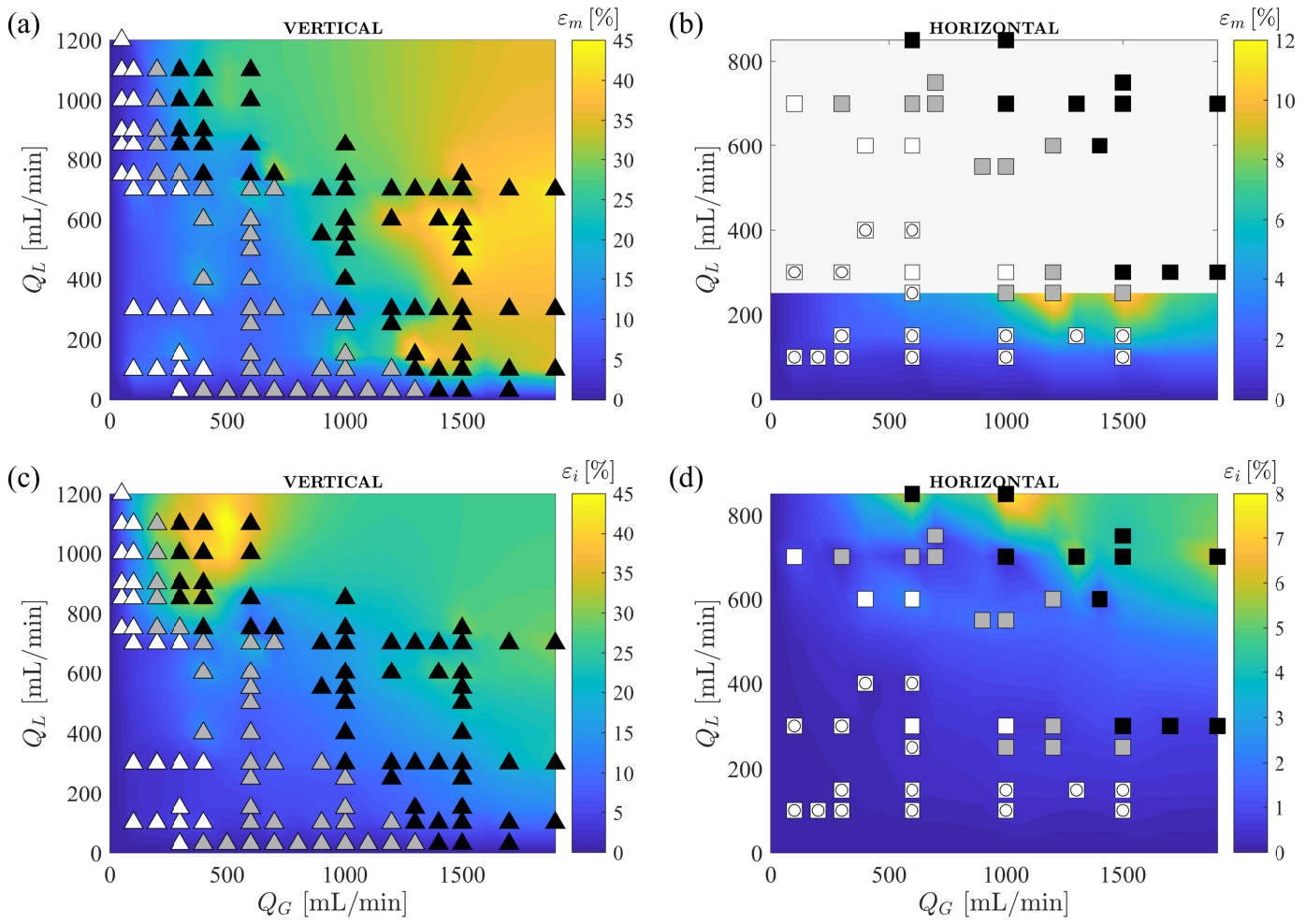

Figure 7: Regime diagrams in the phase space $\left(Q_{L}, Q_{G}\right)$ for the vertical (a,c) and horizontal (b,d) co-current gasliquid flow. The symbols correspond to regimes observed in the horizontal (squares) or vertical (triangles) experiments [white squares with circle inside, pseudo-tricking (PT); white, low activity (LA); gray, transition (T); black, high activity (HA)]. The colormap corresponds to the fraction of joint flow $\varepsilon_{m}$ (a,b) and interface motion $\varepsilon_{i}$ (c,d) in the solid foam. For the horizontal configuration, no estimation of $\varepsilon_{m}$ is possible with the present method for $Q_{L}>250 \mathrm{~mL} / \mathrm{min}$ (gray zone in b).

regimes, the flow regimes are identical when repeating the experiments.

Figures 7a,b display in background the fraction of joint flow area, $\varepsilon_{m}$, while Figures $7 \mathrm{c}, \mathrm{d}$ display the fraction of interface motion, $\varepsilon_{i}$, for the vertical (Figure 7a,c) and horizontal (Figure $7 \mathrm{~b}, \mathrm{~d})$ configurations. For the interpolation of $\varepsilon_{m}$ and $\varepsilon_{i}$ to get a continuous map, both variables were fixed to $\varepsilon_{m}=\varepsilon_{i}=0$ for $Q_{G}=0 \mathrm{~mL} / \mathrm{min}$, as there is no gas phase into the porous medium. For $Q_{L}=0 \mathrm{~mL} / \mathrm{min}$, there is no injection of liquid phase in the solid foam and thus neither joint flow or interface motion, leading again to $\varepsilon_{m}=\varepsilon_{i}=0$. Figure 7 a shows that $\varepsilon_{m}$ increases when the flow goes from the LA to the HA regime. This latter corresponds to a joint flow which occupies a larger region in the solid foam. The correlation between the regime transition and the variable $\varepsilon_{m}$ was not possible to estimate for the horizontal flow. Indeed, for $Q_{L}>250 \mathrm{~mL} / \mathrm{min}$, the method based on morphological analysis failed to compute $\varepsilon_{m}$ in a reliable way. To our knowledge, no signal processing techniques exist at present for such image segmentation, although strong efforts from the Signal Processing community are in progress (see section 5). For $Q_{L} \leq 250 \mathrm{~mL} / \mathrm{min}$, note that $\varepsilon_{m}$ in the horizontal configuration (about $\sim 12 \%$ maximum) is much lower than for the vertical upflow, where $\varepsilon_{m}$ reaches values of about $40-45 \%$. Results for $\varepsilon_{i}$ (Figure 7c,d) lead to similar conclusions: the values are much lower for the horizontal $\left(\varepsilon_{i} \sim 8 \%\right)$ than for the vertical $\left(\varepsilon_{i} \sim\right.$ 


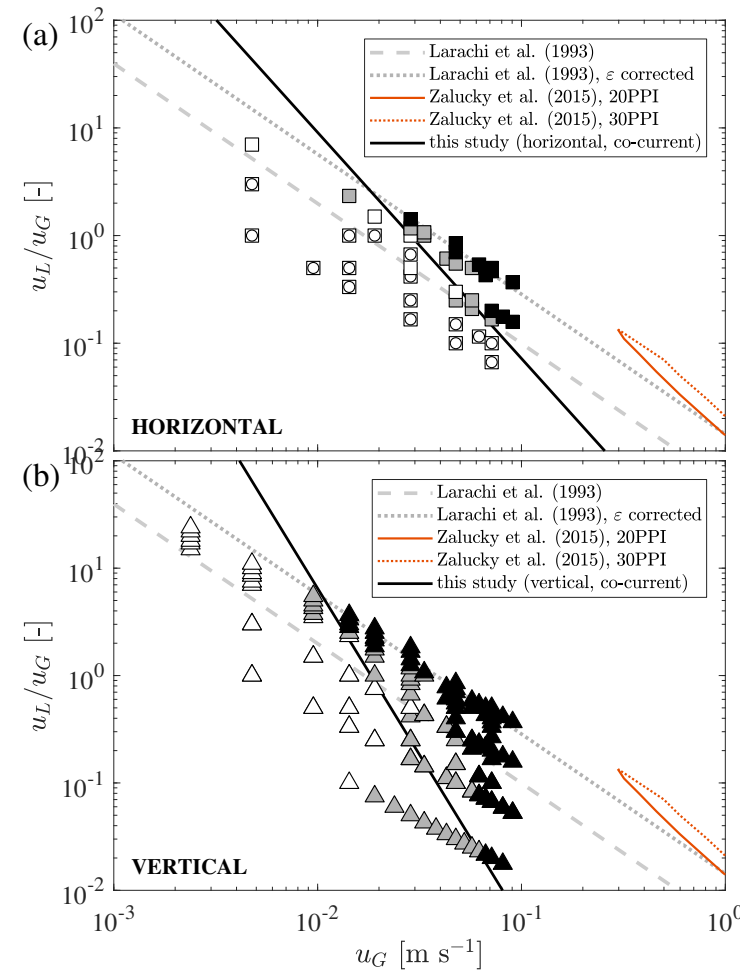

Figure 8: Regime diagram of the hydrodynamic regimes [same symbols than Figure 7, log-log axes, identical for (a,b)]. (a) Horizontal configuration; (b) Vertical upflow. The black solid line represent the transition found in this work for the horizontal (a) and vertical (b) configuration. The gray lines display the transition for packed beds proposed by [48] (dashed), including porosity correction (dotted). The orange lines show the transition predicted for SiSiC foams by [41] for 20PPI (solid) or 30PPI (dashed).

$46 \%$ ) flow. For $\varepsilon_{i}$, however, we observe less correlation between the transition towards the HA regime and strong interface motion. Indeed, at low liquid flow rates $\left(Q_{L} \lesssim 300 \mathrm{~mL} / \mathrm{min}\right)$, we observe almost no change in the (low) value of $\varepsilon_{i}$ whereas a $\mathrm{HA}$ regime is clearly reported (black squares, Figure 7d). The HA regime for the horizontal flow is mostly associated with higher values of $\varepsilon_{i}$ but, similarly, data points for $Q_{L} \lesssim 300 \mathrm{~mL} / \mathrm{min}$ do not exhibit any apparent increase in $\varepsilon_{i}$.

\subsection{Transition between LA ES HA regimes}

Flow regime transitions for gas-liquid flows in solid foams have been reported in the lit- erature since the pioneering work of Stemmet et al. [16]. However, up to now, only few studies have attempted to model it. To our knowledge, models attempting to predict such transition for gas-liquid flow through open cell solid foams have been developed to capture the trickle to pulsing regime transition in trickle bed geometry with co-current downflow [41]. However, as already mentionned at the end of section 4.2 , with the exception of the pseudotrickling regime, none of the flow regimes reported here correspond to the ones observed in trickle beds. The low and high activity regimes, mainly characterized by small or large bubbles, may be a direct consequence of the peculiar confinement of the quasi-2D cell. In particular, we never reported in our experiments a pulsing flow, contrary to what has been observed in a foam packed millichannel $[28,29]$.

Although we cannot propose here a comparison between our experimental data and a model accounting for both the foam and its specific confinement, we can discuss our flow regimes in regards to what is known for more conventional geometries, in particular trickle bed reactors, either filled with packed beds [4851] or open cell solid foams [36, 41]. To do so, we display in Figure 8 the observed regimes in the classical phase diagram $u_{L} / u_{G}$ vs. $u_{G}$, where $u_{G}$ and $u_{L}$ represent the superficial gas and liquid velocities. In a crude approximation, we can describe the regime transition by the empirical law

$$
\frac{u_{L}}{u_{G}}=\beta u_{G}^{-\alpha}
$$

with $\alpha=2.1, \beta=5.7 \times 10^{-4}$ for the horizontal configuration (Figure 8a) and $\alpha=3.1$, $\beta=4.1 \times 10^{-6}$ for the vertical configuration (Figure $8 \mathrm{~b}$ ).

The gray lines in Figure 8 (dashed and dotted) report the transition from the trickle to pulsing regime for co-current air/water downflow in packed beds and unconfined geometry. We consider here the modified version of Charpentier \& Favier's diagram, proposed by 
Larachi et al. (1993) [48]:

$$
\left(\frac{\lambda \psi}{\phi}\right)\left(\frac{\rho_{L}}{\rho_{G}}\right) \frac{u_{L}}{u_{G}}=\left(\frac{\rho_{G}}{\lambda} u_{G}\right)^{-\alpha}
$$

with $\alpha \simeq 1.3[50,52]$. The flow parameters $\lambda$ and $\psi$ are defined by

$$
\begin{aligned}
\lambda & =\left[\frac{\rho_{G}}{\rho_{\text {air }}} \frac{\rho_{L}}{\rho_{\text {water }}}\right]^{1 / 2} \\
\psi & =\frac{\sigma_{\text {water }}}{\sigma_{L}}\left[\frac{\mu_{L}}{\mu_{\text {water }}}\left(\frac{\rho_{\text {water }}}{\rho_{L}}\right)^{2}\right]^{1 / 3}
\end{aligned}
$$

where $\rho_{k}, \sigma_{k}$ and $\mu_{k}$ are the density, surface tension and viscosity of phase $k$ ( $\mathrm{G}$ or $\mathrm{L})$, respectively. The additional parameter $\phi=4.76+0.5 \rho_{G} / \rho_{\text {air }}$ introduced by [48] accounts for pressure effect on the transition in the trickle bed configuration [52]. As the gas is air and liquid water in our experiments, the above parameters are constant and simplify to $\lambda=1, \psi=1$ and $\phi=5.26$. Equation 7 is reported as a dashed gray line in Figures $8 \mathrm{a}$ and $8 b$.

To account for the foam very high porosity $(90 \%)$ respect to classical packed beads ( $\simeq 40 \%)$, we follow Gianetto et al. [53] and introduce a correction accounting for the material porosity (in $u_{G} / \epsilon$, dotted gray lines, Figures 8a,b). This correction shifts the transition line without modifing its slope. Both scaling laws capture roughly the order of magnitude of the transition but, as expected, cannot account for the experimental observations in our confined, quasi-2D foam. As a comparison, we also reported in Figure 8a,b the model proposed by Zalucky et al., 2015 [41]. This model is based on the film stability model proposed by Grosser et al. in 1988 [12], and accounts fairly for the trickle to pulsing regime transition in unconfined, $\mathrm{SiSiC}$ foams of different porosities. This model has been specifically developed to capture this transition - once again, not the one we report in our experiments - and is based on several empirical measurements or fitting parameters such as the Ergun parameters, the static liquid holdup, or the relative permeabilities. It is out of the scope of this work to adapt such model to our configuration, as it is probable that the confinement of our experiment and the buoyancy effects (upward vertical or co-current horizontal) have different consequences on the macroscopic flow. However, as a comparison, we report in Figures 8a,b the regime transition for $\mathrm{SiSiC}$ foams of 20PPI (solid orange line) or 30 PPI (dashed orange line). Although the gas velocity is outside our experimental range, we can infer that this model, once again, is not adapted to describe the regime transition observed in our experiments.

\section{Conclusion}

The hydrodynamics of a multiphase gasliquid flow through a thin sheet of open-cell solid foam of $90 \%$ porosity was investigated experimentally. The goal of this work was to quantify the flow regimes and phases interaction in a confined environment, here a quasi$2 \mathrm{D}$ reactor. For a co-current air/water flow, we explored a wide range of gas and liquid flow rates, $Q_{G}$ and $Q_{L}$. In addition, we also compared the flow patterns when changing the buoyancy in the system, from a vertical upflow to a horizontal configuration. To quantify the phases interaction, we introduced two new quantities computed from direct flow visualization: the fraction of joint flow area, $\varepsilon_{m}$, and of interface motion, $\varepsilon_{i}$. These quantities make it possible to distinguish between two main flow regimes which appear when varying $\left(Q_{G}, Q_{L}\right)$ : the low activity regime (LA), characterized by small bubbles or chimneys and the high activity regime (HA), characterized by large bubbles. The pseudo-trickling regime (PT), which presents similarities with classical trickle flows, only exists in the horizontal configuration. The high activity regime is directly linked to an increase in $\varepsilon_{m}$ and $\varepsilon_{i}$, although the correlation is not so well-marked in the horizontal setup. In addition, we find a striking effect of buoyancy, with a strong increase of both $\varepsilon_{m}$ and $\varepsilon_{i}$ for 
the vertical co-current upward flow respect to the horizontal flow. This configuration would therefore optimize the phases surface contact area for further applications to chemical reactions.

The image analysis algorithm in its present version fails in capturing correctly the gas and liquid phase location at high liquid flow rate. The detection under these conditions is difficult as the images are strongly textured, and would require advanced signal processing tools to distinguish correctly the gas and liquid phases. A collaboration in progress with the Signal Processing community lead to promising preliminary results, but the time to separate the gas and liquid phases on a single image (about 1.5 hours) and the algorithm instability are still prohibiting large data sets analysis.

For both the horizontal and vertical flows, the transition between the low activity (LA) and high activity (HA) regime is smooth. An empirical law is proposed for the flow regime transition in each configuration. In absence of any existing model for two-phase flows in quasi2D foams, we discussed our results in comparison to the regime transition proposed by Larachi et al. [48] (dense packed beds) or Zalucky et al. [41] ( $\mathrm{SiSiC}$ open cell solid foams) for two-phase co-current downflows. The results show that for a relatively low ratio of liquid to gas superficial velocity $\left(u_{L} / u_{G} \leqq 1\right)$, the transition to the high activity regime occurs at a much lower gas flow rate than the pulsing flow transition in trickle bed reactors - either with dense packed beds or foams. This could represent an advantage of this type of quasi-2D configuration in terms of chemical engineering applications, in particular in the vertical geometry.

A model explaining the transition between the different regimes could not yet be implemented successfully. A possible strategy, at least for the vertical configuration, could be to consider the transition between columns of small bubbles, observed in the low activity regime, and columns of large bubbles, observed in the high activity regime, as a coalescence phenomenon [34]. Considering that, in the low activity regime, the typical bubble diameter $d$ is roughly constant, we can model the gas upflow, in absence of liquid flow $\left(Q_{L}=0\right)$, as $N$ columns of bubbles rising through the porous medium, with $N \simeq 3-4$. Note that $N$ in the experiments is always smaller than the gas injectors number, due to the formation of a gas pocket in the lower part of the foam. Bubbles are emitted in each of the $N$ columns at constant flow-rate $Q_{G} / N$, at constant time steps $\tau=\xi / v$ where $\xi$ is the typical distance between two bubbles center of mass in each column and $v$ the bubble velocity. Preliminary measurements of bubbles velocity have been performed in the foam, and surprisingly, $v$ is of the order of the bubble rising speed in the quasi$2 \mathrm{D}$ cell without the foam. We can thus take, as a first approximation, the law proposed by Roudet [44] for Reynolds number between 10 and 1000, which is the case in most experiments: $v \simeq 0.5 \sqrt{g d}$. When increasing the gas flow-rate, the bubbles are emitted at shorter time steps $\tau$ (or distance $\xi$ ). At the transition between the low and high activity regime, $\xi=d$ and they coalesce to form larger bubbles. We thus get the critical gas flow-rate as the bubble volume, $\pi\left(d^{2} / 4\right) e$, divided by the time step $\tau$, weighted by the number of bubble columns $N$ :

$$
Q_{g}^{c}=N \frac{\pi d^{2}}{4} e\left(\frac{v}{d}\right) .
$$

Replacing $v$ by the above expression leads to

$$
Q_{g}^{c}=N \frac{\pi}{8} e \sqrt{g} d^{3 / 2}
$$

where $g=9.81 \mathrm{~m} / \mathrm{s}^{-2}$ is the gravitational acceleration. Considering $d \simeq 1 \mathrm{~cm}$ and $N \simeq 3-4$ leads to $Q_{G}^{c} \simeq 387-516 \mathrm{~mL} / \mathrm{min}$, compatible with the transition found in Figures 7a,c for the vertical configuration at $Q_{L}=0$.

Although this crude model captures fairly well the transition in absence of liquid flow-rate 
for the vertical upflow, it would require strong improvements to account for the influence of the liquid flow. Indeed, this latter cannot be simply introduced as an additionnal advection velocity, which would lead to $Q_{G}^{c}$ increasing with $Q_{L}$, which is not observed in the experiments. On the contrary, $Q_{G}^{c}$ decreases when $Q_{L}$ increases (Figures 7a,c). A more elaborated model should maybe consider the competition between two bubble populations, or a dependence of $d$ on $Q_{L}$. It is the goal of a future work.

\section{Acknowledgments}

The authors acknowledge F. Bornette and F. Campoli for their contribution to the experiment design and setup, and S. Joubaud for his help in measuring the cell gap with laser profilometer. This work was supported by the LABEX iMUST (ANR-10-LABX-0064) of Université de Lyon, within the program "Investissements d'Avenir" (ANR-11-IDEX-0 0 07) operated by the French National Research Agency (ANR). The authors wish to thank three anonymous referees for comments which greatly improved this work.

[1] MP Dudukovic, F Larachi, and PL Mills. Multiphase reactors-revisited. Chemical Engineering Science, 54(13-14):1975-1995, 1999.

[2] MF Malone and MF Doherty. Reactive distillation. Industrial \& Engineering Chemistry Research, 39(11):3953-3957, 2000.

[3] A Hoffmann, I Ausner, J-U Repke, and G Wozny. Fluid dynamics in multiphase distillation processes in packed towers. Computers $\&$ chemical engineering, 29(6):1433-1437, 2005.

[4] Ö Yildirim, AA Kiss, N Hüser, K Leßmann, and EY Kenig. Reactive absorption in chemical process industry: a review on current activities. Chemical engineering journal, 213:371-391, 2012.

[5] MW Losey, MA Schmidt, and KF Jensen. Microfabricated multiphase packed-bed reactors: characterization of mass transfer and reactions. Industrial $\&$ engineering chemistry research, 40(12):2555-2562, 2001.

[6] V Hessel, P Angeli, A Gavriilidis, and H Löwe. Gas-liquid and gas-liquid-solid microstructured reactors: contacting principles and applica- tions. Industrial $\mathcal{G}$ engineering chemistry research, 44(25):9750-9769, 2005.

[7] N Márquez, P Castaño, M Makkee, JA Moulijn, and MT Kreutzer. Dispersion and holdup in multiphase packed bed microreactors. Chemical Engineering 83 Technology: Industrial Chemistry-Plant Equipment-Process Engineering-Biotechnology, 31(8):1130-1139, 2008.

[8] C-Y Wang. Fundamental models for fuel cell engineering. Chemical reviews, 104(10):4727-4766, 2004.

[9] K-M Kan and PF Greenfield. Multiple hydrodynamic states in cocurrent two-phase downflow through packed beds. Industrial \& Engineering Chemistry Process Design and Development, 17(4):482-485, 1978.

[10] J Levec, AE Saez, and RG Carbonell. The hydrodynamics of trickling flow in packed beds. part ii: Experimental observations. AIChE journal, 32(3):369-380, 1986.

[11] AE Saez, RG Carbonell, and J Levec. The hydrodynamics of trickling flow in packed beds. part i: Conduit models. AIChE Journal, 32(3):353-368, 1986.

[12] K. Grosser, R. G. Carbonell, and S. Sundaresan. Onset of pulsing in two-phase cocurrent downflow through a packed bed. AIChE J., 34(11):18501860, 1988.

[13] MP Duduković, F Larachi, and PL Mills. Multiphase catalytic reactors: a perspective on current knowledge and future trends. Catalysis reviews, 44(1):123-246, 2002.

[14] D Loudon, W van der Merwe, and W Nicol. Multiple hydrodynamic states in trickle flow: quantifying the extent of pressure drop, liquid holdup and gas-liquid mass transfer variation. Chemical engineering science, 61(22):7551-7562, 2006.

[15] R Joubert and W Nicol. Trickle flow liquid-solid mass transfer and wetting efficiency in small diameter columns. The Canadian Journal of Chemical Engineering, 91(3):441-447, 2013.

[16] CP Stemmet, JN Jongmans, J Van der Schaaf, BFM Kuster, and JC Schouten. Hydrodynamics of gas-liquid counter-current flow in solid foam packings. Chemical engineering science, 60(22):64226429, 2005.

[17] CP Stemmet, J Van Der Schaaf, BFM Kuster, and JC Schouten. Solid foam packings for multiphase reactors: modelling of liquid holdup and mass transfer. Chemical Engineering Research and Design, 84(12):1134-1141, 2006.

[18] CP Stemmet, M Meeuwse, J Van der Schaaf, BFM Kuster, and JC Schouten. Gas-liquid mass transfer and axial dispersion in solid foam packings. Chemical Engineering Science, 62(1820):5444-5450, 2007. 
[19] CP Stemmet, F Bartelds, J Van der Schaaf, BFM Kuster, and JC Schouten. Influence of liquid viscosity and surface tension on the gas-liquid mass transfer coefficient for solid foam packings in cocurrent two-phase flow. Chemical Engineering Research and Design, 86(10):1094-1106, 2008.

[20] J Lévêque, D Rouzineau, M Prévost, and M Meyer. Hydrodynamic and mass transfer efficiency of ceramic foam packing applied to distillation. Chemical Engineering Science, 64(11):2607-2616, 2009.

[21] J Grosse and M Kind. Hydrodynamics of ceramic sponges in countercurrent flow. Industrial \& Engineering Chemistry Research, 50(8):4631-4640, 2011.

[22] F. Lali, F.-A. Pahner, and R. Lange. Modeling and simulation of the hydrogenation of $\alpha$ methylstyrene on catalytically active metal foams as tubular reactor packing. International Journal of Chemical Engineering, 2016:7082381, 2016.

[23] P. W. A. M. Wenmakers, J. van der Schaaf, B. F. M. Kuster, and J. C. Schouten. Enhanced liquid-solid mass transfer by carbon nanofibers on solid foam as catalyst support. Chemical Engineering Science, 65:247-254, 2010.

[24] P. W. A. M. Wenmakers, J. van der Schaaf, B. F. M. Kuster, and J. C. Schouten. Comparative modeling study on the performance of solid foam as a structured catalyst support in multiphase reactors. Ind. Eng. Chem. Res., 49:5353-5366, 2010.

[25] R Philippe, M Lacroix, L Dreibine, C Pham-Huu, D Edouard, S Savin, F Luck, and D Schweich. Effect of structure and thermal properties of a Fischer-Tropsch catalyst in a fixed bed. Catalysis Today, 147:S305-S312, 2009.

[26] M Saber, TT Huu, C Pham-Huu, and D Edouard. Residence time distribution, axial liquid dispersion and dynamic-static liquid mass transfer in trickle flow reactor containing $\beta$-SiC open-cell foams. Chemical Engineering Journal, 185:294-299, 2012.

[27] J Lévêque, R Philippe, M-L Zanota, V Meille, F Sarrazin, L Baussaron, and C De Bellefon. Hydrodynamics and mass transfer in a tubular reactor containing foam packings for intensification of GLS catalytic reactions in co-current up-flow configuration. Chemical Engineering Research and Design, 109:686-697, 2016.

[28] J-N Tourvieille, R Philippe, and C de Bellefon. Milli-channel with metal foams under an applied gas-liquid periodic flow: flow patterns, residence time distribution and pulsing properties. Chemical Engineering Science, 126:406-426, 2015.

[29] J-N Tourvieille, R Philippe, and C de Bellefon. Milli-channel with metal foams under an applied gas-liquid periodic flow: external mass transfer performance and pressure drop. Chemical Engineering Journal, 267:332-346, 2015.
[30] B Dietrich, W Schabel, M Kind, and H Martin. Pressure drop measurements of ceramic spongesdetermining the hydraulic diameter. Chemical Engineering Science, 64(16):3633-3640, 2009.

[31] K Pangarkar, TJ Schildhauer, JR van Ommen, J Nijenhuis, F Kapteijn, and JA Moulijn. Structured packings for multiphase catalytic reactors. Industrial \& engineering chemistry research, 47(10):3720-3751, 2008.

[32] RR Zapico, P Marín, FV Díez, and S Ordóñez. Liquid hold-up and gas-liquid mass transfer in an alumina open-cell foam. Chemical Engineering Science, 143:297-304, 2016.

[33] M Serres, M-L Zanota, R Philippe, and V Vidal. On the stability of taylor bubbles inside a confined highly porous medium. International Journal of Multiphase Flow, 85:157-163, 2016.

[34] M Serres, T Maison, R Philippe, and V Vidal. A phenomenological model for bubble coalescence in confined highly porous media. International Journal of Multiphase Flow, 105:134-141, 2018.

[35] M Schubert, G Hessel, C Zippe, R Lange, and $\mathrm{U}$ Hampel. Liquid flow texture analysis in trickle bed reactors using high-resolution gamma ray tomography. Chemical Engineering Journal, 140(13):332-340, 2008.

[36] J Zalucky, M Wagner, M Schubert, R Lange, and $\mathrm{U}$ Hampel. Hydrodynamics of descending gasliquid flows in solid foams: Liquid holdup, multiphase pressure drop and radial dispersion. Chemical Engineering Science, 168:480-494, 2017.

[37] I Mohammed, T Bauer, M Schubert, and R Lange. Gas-liquid distribution in tubular reactors with solid foam packings. Chemical Engineering and Processing: Process Intensification, 88:10-18, 2015.

[38] A Wongkia, F Larachi, and S Assabumrungrat. Hydrodynamics of countercurrent gas-liquid flow in inclined packed beds-A prospect for stretching flooding capacity with small packings. Chemical Engineering Science, 138:256-265, 2015.

[39] S Calvo, D Beugre, M Crine, A Léonard, P Marchot, and D Toye. Phase distribution measurements in metallic foam packing using X-ray radiography and micro-tomography. Chemical engineering and processing: Process intensification, 48(5):1030-1039, 2009.

[40] X Ou, X Zhang, T Lowe, R Blanc, M Rad, Y Wang, N Batail, C Pham, N Shokri, and A A Garforth. X-ray micro computed tomography characterization of cellular $\mathrm{SiC}$ foams for their applications in chemical engineering. Materials Characterization, 123:20-28, 2017.

[41] J Zalucky, F Moller, M Schubert, and U Hampel. Flow regime transition in open-cell solid foam packed reactors: Adaption of the rela- 
tive permeability concept and experimental validation. Industrial \& Engineering Chemistry Research, 54(40):9708-9721, 2015.

[42] AM Dashliborun, A Füssel, and F Larachi. Prospect of open-cell solid foams for floatingplatform multiphase reactor applicationsmaldistribution susceptibility and hydrodynamic behavior. Chemical Engineering Journal, 332:596-607, 2018.

[43] P. Aussillous and D. Quéré. Quick deposition of a fluid on the wall of a tube. Phys. Fluids, 12(10):2367-2371, 2000.

[44] M. Roudet. Hydrodynamique et transfert de masse autour d'une bulle confinée entre deux plaques. $\mathrm{PhD}$ thesis, Institut National Polytechnique de Toulouse, 2008. $131 \mathrm{p}$.

[45] R. A. Holub, M. P. Duduković, and P. A. Ramachandran. Pressure drop, liquid holdhop, and flow regime transition in trickle flow. AIChE J., 39(2):302-321, 1993.

[46] A. Bansal, R. K. Wanchoo, and S. K. Sharma. Flow regime transition in a trickle bed reactor. Chem. Eng. Comm., 192:1046-1066, 2005.

[47] F. Cavani, G. Centi, S. Perathoner, and F. Trifirò. Sustainable industrial chemistry: Principles, tools and industrial examples. Wiley VCH, 2009. 621 p.

[48] F. Larachi, A. Laurent, G. Wild, and N. Midoux. Effet de la pression sur la transition ruisselantpulsé dans les réacteurs catalytiques à lit fixe arrosé. Canadian Journal of Chemical Engineering, 71:319-321, 1993.

[49] J-C Charpentier and M Favier. Some liquid holdup experimental data in trickle-bed reactors for foaming and nonfoaming hydrocarbons. AIChE Journal, 21(6):1213-1218, 1975.

[50] A Attou and C Boyer. Revue des aspects hydrodynamiques des réacteurs catalytiques gaz-liquidesolide à lit fixe arrosé. Oil \& Gas Science and Technology, 54(1):29-66, 1999.

[51] A Attou, C Boyer, and G Ferschneider. Modelling of the hydrodynamics of the cocurrent gas-liquid trickle flow through a trickle-bed reactor. Chemical Engineering Science, 54(6):785-802, 1999.

[52] D. Schweich. Génie de la réaction chimique. Tec \& Doc, 2001. 610 p.

[53] A. Gianetto, G. Baldi, V. Specchia, and S. Sicardi. Hydrodynamics and solid-liquid contacting effectiveness in trickle-bed reactors. AIChE J., 24:1087-1104, 1978.

\section{AppendixA. Reproducibility of the flow regimes}

The reproducibility of the flow regimes was tested by repeating several experiments with the same imposed flow rates $\left(Q_{G}, Q_{L}\right)$. The results are highlighted in Figure A.9 which displays all the flow patterns identified in the regime diagram $\left(Q_{G}, Q_{L}\right)$, where the frames indicate repetitions of the same experiment.

For most of these multiple-checked points, the flow pattern is the same and the regime (LA, T or HA) unequivocal. Only a few points at the transition between the LA and HA regimes lead to a different identification, for the following gas and liquid flow rates $\left(Q_{G}, Q_{L}\right)$ (in $\mathrm{mL} / \mathrm{min})$ : $(600,300) ;(1000,300) ;(1300,100)$. This uncertainty in the transition vicinity confirms that the transition between LA and HA is smooth, and correctly described by the introduction of the transition regime $(\mathrm{T})$. 


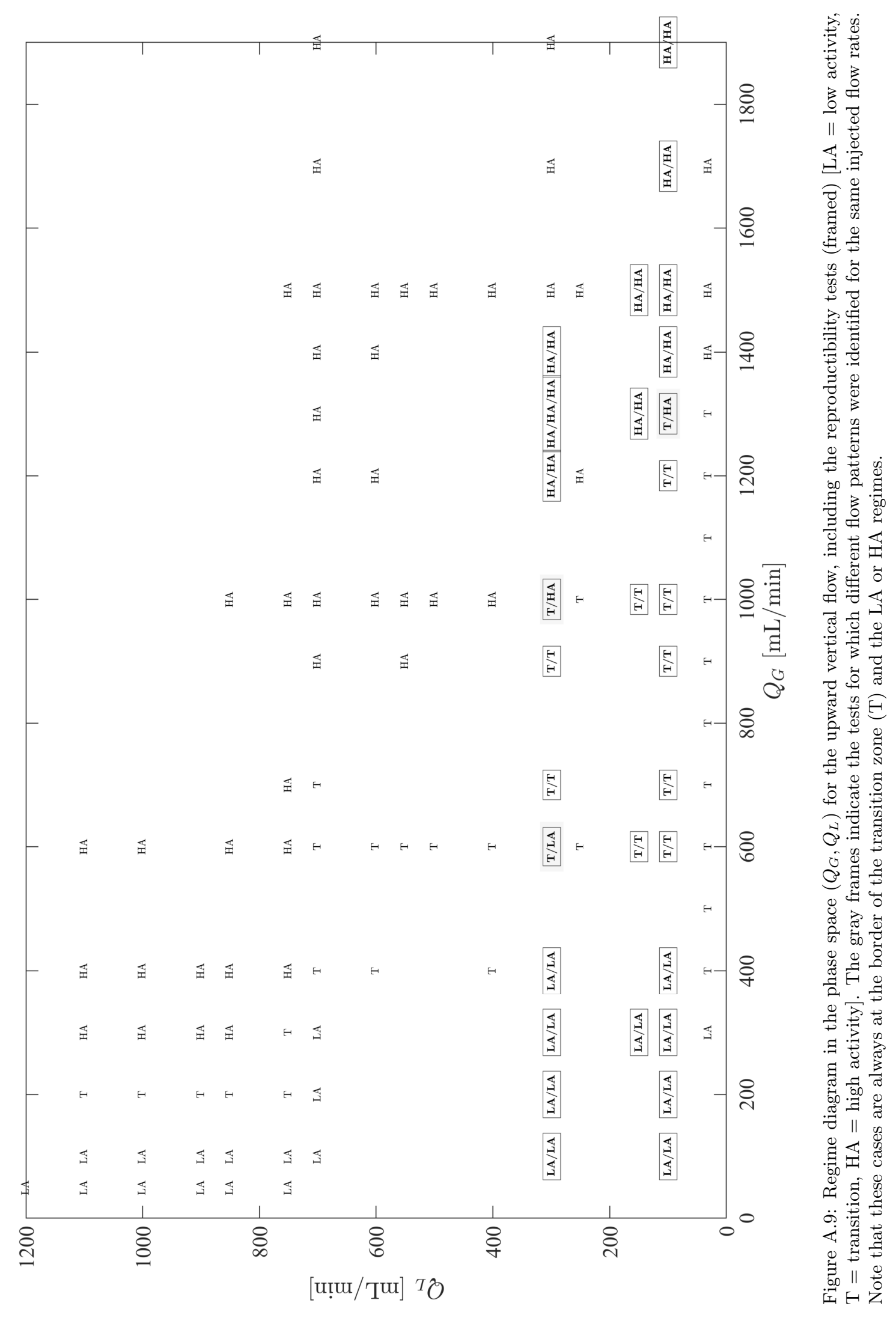

